\title{
The Health of Preschoolers in Child Care Settings: Some Possibilities for Nursing Intervention
}

\author{
Winnie O. Willis \\ University of Michigan School of Public Health
}

\section{Introduction}

According to a recent estimate there are 6 million children in the United States under the age of 6 who have working mothers. Approximately $45 \%$ of the children under 6 are in child care settings for some portion of their daily care, with well under $10 \%$ of these enrolled in licensed day care centers (Keyserling, 1972; U.S. Senate, 1974). The variety of settings include family day care homes, nursery schools, day care centers, cooperative child care centers, and play groups.

Family day care homes are private homes in which three or more (but fewer than six) unrelated children receive care and supervision. A nursery school is a daytime group facility that has as its main objective a developmental program for preschool children and whose staff meet educational qualifications established by a Department of Education. A day care center is a daytime group facility that gives care for preschool children away from their homes but that need not employ staff approved by the Department of Education, though they must have experience in child care. Its objective is to promote individual development (Michigan Department of Social Services, 1973). A cooperative child care center is a facility eligible for licensure that has a policy of including parents on the staff. A play group is an informal but regular arrangement in which mothers exchange hours or days of child care in individual homes. Regardless of the setting or its primary objective, the need to make health services available to

Requests for reprints should be sent to Winnie O. Willis, RN, Department of Maternal and Child Health, School of Public Health, University of Michigan, 109 S. Observatory, Ann Arbor, Michigan 48104. 
this population has long been recognized. The achievement of effective organization and delivery is the present challenge.

\section{Present Services for Preschoolers}

It is acknowledged here that whether children are enrolled in child care or not, a comprehensive and accountable health delivery mechanism for this neglected age group is long overdue. In spite of the seeming proliferation of services and funding sources, such as immunization and other specialty clinics, well-child conferences, screening programs, and Medicaid, the majority of this country's preschoolers either receive no care at all or fall into the cracks between primary care, early detection, and treatment (American Academy of Pediatrics, 1970). A day care health program that focuses on primary care is as logical as a school health program. It would have the potential for promoting the early diagnosis and treatment of problems often overlooked until school age. A natural flow of health data from preschool care to school would develop (American Academy of Pediatrics, 1970).

\section{Observation of Need by Child Care Workers}

As in any preschool population, those attending child care settings often present signs and symptoms of illness. As important as the need for services to the ill child is the need for services that emphasize illness prevention and health maintenance. Teachers in child care settings have expressed the belief that a nurse who is knowledgeable in the area of pediatrics and who would be on the premises or able to come out to see individual children whenever called, would improve the quality of decision making regarding the type of health care both the well and the ill child needs. They feel that this kind of nursing intervention would reduce the number of unnecessary hospital and doctor's office visits that they make with the children, as well as reduce work days lost, hence income forfeited, by many parents. Many health professionals and agencies do not see this proposal as fiscally sound in view of the high cost of nursing services and the increasing number of child care settings. And if the cost were left with the individual centers, it would be the rare one indeed that could afford to hire a nurse on even a weekly, much less a daily, basis. These constraints call for the development of alternative plans that make maximal use of available resources. Effective referral to existing community health services is more cost effective from the standpoint of continuity of care and resource utilization. 


\section{Possible Service Models}

Questions to be addressed in view of the need for a more organized health component in child care settings include: Is the nurse the most logical health provider to carry out this component? What would be the specific functions of the nurse? What would be the role of the staff? From the standpoint of manpower availability and the services requested above, the nurse is the most logical provider in this setting. It is recognized that the nursing role is complementary to the roles of other health care providers, including the pediatrician, the mental health worker, and the social worker, and that planning for each child's health needs should be done in consultation and collaboration with them.

Nursing coordination of the health care of children in child care settings has been successfully demonstrated in Head Start programs. Though Head Start programs have a variety of models for nursing service, the two most common have been: (a) a nurse hired especially by one project or by a group of projects geographically close; (b) a public health nurse who is employed by a health department and serves the Head Start project by contractual arrangement. Each model has some transferability to other child care settings. Modifications will be necessary due to budgetary constraints.

The public health nurse is in a unique position to work with other health and human services providers to formulate a plan for comprehensive health care delivery. The public health nurse can initiate contact with various providers and determine the extent to which each would be willing and able to provide services to this population. Specific referrals could be made once available providers are identified. An essential and challenging part of that referral process is actually effecting the parent, child, and provider interface for initial care and follow-up.

\section{Nursing Intervention and Some Rationale}

The specific functions of the nurse will fall in the general areas of working with parents, staff, health and human services providers, and public and private constituencies. Since consultation time in the centers may be limited, the nurse will have mostly indirect interaction with the children while developing and utilizing the abilities of center staff and parents to teach health habits and behaviors and to perceive and refer health problems. The nurse can meet with parents either individually or in groups to discuss parental concerns, family influences 
on child health, and methods of acquiring access to services. Prevention of illness and self-help are also important. With the child care staffs, the nurse can:

a. review child growth and development as it affects health and within the context of developmental needs;

b. discuss common health problems of children;

c. direct staff learning activities geared toward increasing staff competency in recognizing deviations in behavior and appearance that may be indicative of illness;

d. direct learning experiences and collect reference materials to develop staff decision-making abilities when it is determined that a child is ill.

Before proceeding with the discussion of nursing function, it would be well to present some rationale for the utilization and cultivation of staff abilities to make decisions about the proper disposition of an ill child. Because decision making about the state of wellness or illness can be placed on a manpower continuum, beginning with nonmedical decision makers, expanding to paramedical decision makers, and then to medical decision makers, it is reasonable to assume that child care staff persons can be trained to make nonmedical decisions about wellness or illness if given adequate training and afforded continuing supervision and consultation (Hunter, 1970).

They are already making the decisions without benefit of training. They do have some loose guidelines (as a requirement of licensure) in the form of parent authorization for emergency care and the pediatrician's name. They report a high level of staff anxiety (due to lack of health background) if they make the decision not to take the child for medical help. This anxiety underlies many decisions to take the child for care when it is not indicated.

An example of staff ability to recognize health problems is reported by Meyer, McDermott, Grilson, and Frey (1971), in a project conducted by North western University, the Infant Welfare Society of Chicago, and the De Paul Settlement and Day Nursery. In this study, over $10 \%$ of the children's health problems were reported identically by physical exam and staff teacher. Ten percent corroboration may seen good or not so good, depending on your vantage point, but it should be noted that the staff teachers in this project were not being formally taught child health observation or skills of problem recognition. Learning seemed to take place in weekly meetings with the health team, where individual problems were discussed and plans for follow-up were made.

Many child care centers routinely call the parent at work when a 
health problem occurs in order to ascertain how the parent wants it to be handled. Some parents allow the child to be taken for medical treatment immediately; others wait until they can pick up the child themselves after work, if only a couple of hours remain before day's end; still others leave work to come for their child, but distance and transportation may impede their arrival. It is in the latter two cases that the child care worker will need to have skills to care temporarily for a child. It is also important to note that in most states, criteria for licensure require that a "sick bay" area be provided within the center. From this, one can infer that persons concerned with child welfare expect minor health problems to occur from time to time for which special provision should be made. The implication is that this is for a short period of time under the supervision of the child care worker.

It is appropriate to mention here that consultation with a public health nurse is always available by phone simply by calling the local health department. The particular nurse serving that district who is familiar with the community can be requested; sometimes the nurse may have already established relationships with area child care settings.

Child care workers also feel the nurse could give specific treatments to ill children in the centers. It can be expected that the majority of children enrolled would require preventive care and health mainte-nance service rather than treatment. However, the qualifications and skills of the nurse, the policies of the agency employing the nurse, and the nature of the child's illness will help to determine the extent of on-site treatments. A less obvious but no less important consideration is whether treatment for illness should be offered in a setting where the major objective is not the provision of medical care. It is ventured here that under existing patterns of day care operation and mechanisms of health care delivery, on-site treatment for illness is neither feasible nor appropriate. Notable exceptions to this are the Head Start program and some isolated programs in communities where health services are unavailable or inaccessible.

As we return to the discussion of nursing function, another extremely important activity with the staff is assisting with the development of health policies that will govern all center activities regarding the children's health. A policy is a definite course or mode of action that serves as a guide for decision making. Health policies may develop from staff or parent observations of the need for a consistent and public statement of intent, e.g., "Only medicines prescribed by an M.D. will be given." They may also be a restatement of state licensure requirements into operational terms as a particular center states 
its understanding of an intent to carry out a mandate, e.g., exclusion for communicable disease. The area of health policies is even more unfamiliar to child care center staffs than specific illness conditions, so it becomes necessary for the nurse to convince the staff of their necessity, as well as to help with the writing, dispersal, and proper utilization of them. It is not an easy or quick undertaking, but requires commitment of time and repeated efforts in staff development and parent education.

Two University of Michigan School of Public Health graduate students in Public Health Nursing worked with two different day care center directors and staffs for a period of four months. Their responsibilities were as outlined in the preceding paragraphs. In periodic meetings with their faculty supervisor, each of them reported extreme difficulty in communicating the need for and use of health policies. The centers were currently abiding by state licensing regulations and, therefore, could not see the need to have additional written statements to bind them to more procedures.

Both nurses legitimized these staff concerns and the evident resistance. They showed receptivity to questions and comments and kept the subject before the staff through the initiation of discussions about policy usefulness in clarifying center goals and activities, as well as in communicating with parents and the community. At the end of the four-month period, one of the centers had a skeleton outline of policy statements, which needed a great deal more work and refinement. The other center had not even begun to write. This experience again points up the individuality of various staff groups and the long consultation needed.

Parent education regarding alternatives for health care and eligibility for publicly funded programs could be presented. These programs include well-child conferences, children and youth projects, crippled children's services, the Early Periodic Screening Diagnosis and Treatment programs, Department of Social Services programs that offer funding for child care, community mental health programs, and, finally, immunization programs.

In working with public and private constituency groups, nurses are carrying out the advocacy role. They can be more effective in the role if they are willing to serve on advisory boards and in child care action or planning groups. The local Community Coordinated Child Care Council or the advisory board of one particular center is an excellent means for providing input. In either situation or in a variety of other child-centered groups, nurses' willingness to invest time and energy will be capitalized upon. 
As states move toward promulgation of more sophisticated rules and regulations governing the care of children in child care settings, and as these rules contain broader implications for health, it is obvious that the nurse must take an active role in the processes that shape legislation also. In the Michigan legislature in 1973, there were at least 15 bills introduced that contained implications for child care. Advocacy groups are in the position to monitor and comment upon proposed legislation and, in some cases, to make suggestions for the drafting of needed legislation. Testimony presented at public hearings is another important form of advocacy.

\section{Summary}

One of the most difficult challenges facing nurses as they contemplate their potential functions in child care settings is making the decision to become involved. In the constant social and political state of insufficient funds and frozen positions, there are very few public health agencies that have designated child care settings as a program priority. It is, therefore, likely that many nurses who undertake it as a personal priority will not receive the agency endorsement nor the more necessary encouragement and reward for this endeavor. It then rests with the individual nurses to assess their own commitment to the concept of child health. Is this a vulnerable population that is amenable to the kind of intervention that nursing has to offer? If the answer is yes, then the decision to begin must be made now.

\section{References}

American Academy of Pediatrics. Delivery of health care to children. In Lengthening shadows. Evanston, Ill,: 1970.

Hunter, G. T. Health care through Head Start. Children, 1970, 17, 149-153.

Keyserling, M. D. Windows on day care. New York: National Council of Jewish Women, 1972.

Meyer, R., McDermott, J., Gilson, G., \& Frey, J. Raising the level of child health in day care. Child Welfare, 1971, 50(2), 112-117.

Michigan Department of Social Services. Nursery schools and day care centers: Requirements for licensing and recommended standards. Lansing, Mich.: 1973.

U.S. Senate Committee on Finance. Child care data and materials. Washington, D.C.: U.S. Government Printing Office, 1974. 